\title{
FEDERALISMO COOPERATIVO E EDUCAÇÃO NO BRASIL: 30 ANOS DE OMISSÕES E AMBIVALÊNCIAS*
}

\author{
Gilda Cardoso de Araujo ${ }^{1}$ (D
}

\begin{abstract}
RESUMO: O artigo teve por objetivo problematizar como as omissóes e as ambivalências quanto à regulamentação da cooperação federativa vêm propiciando o delineamento e a difusão de formas de colaboração oriundas de organizaçóes de interesses empresariais que são antagônicas aos interesses da organização da educação sob a forma do sistema nacional. A partir de pesquisa bibliográfica e documental, são discutidas a cooperação federativa em matéria educativa, as omissóes do Legislativo quanto à sua regulamentação e a atuação ambivalente do Ministério da Educaçáo e da Secretaria de Articulação dos Sistemas de Ensino. As conclusóes indicam o avanço das proposiçóes das organizaçóes de interesses empresariais em detrimento da adequada regulamentaçáo da matéria por meio de Lei Complementar.
\end{abstract}

Palavras-chave: Federalismo cooperativo. Regime de colaboração. Sistema Nacional de Educaçáo. Arranjos de desenvolvimento da educação. Movimento Colabora Educação.

\section{COOPERATIVE FEDERALISM AND EDUCATION IN BRAZIL: 30 YEARS OF OMISSIONS AND AMBIVALENCES}

\begin{abstract}
The purpose of this article was to discuss how the omissions and ambivalences regarding the regulation of federative cooperation have led to the delineation and diffusion of forms of collaboration originating from organizations of business interests that are antagonistic to the interests of the organization of education in the form of the national system. From a bibliographical and documentary research, federal cooperation in education matters, the omissions of the Legislative as to its regulation and the ambivalent performance of the Ministry of Education and the Secretariat of Articulation of Teaching Systems are discussed. The conclusions indicate the progress of the proposals of organizations of business interests to the detriment of the appropriate regulation of the matter by means of a Complementary Law.
\end{abstract}

Keywords: Cooperative federalism. Collaboration regime. National System of Education. Education development arrangements. Movement Collaborates Education.

\footnotetext{
*Este artigo vincula-se ao projeto de pesquisa Regulamentação e Implementação do Sistema Nacional de Educação no Brasil: Relações Intergovernamentais para a Garantia do Direito à Educação, com financiamento do Conselho Nacional de Desenvolvimento Científico e Tecnológico (CNPq) (Processo no 427959/2016).

${ }^{1}$ Universidade Federal do Espírito Santo - Vitória (ES), Brasil. E-mail: gilda.araujo@ufes.br DOI: 10.1590/ES0101-73302018200031
} 


\title{
FÉDÉRALISME COOPÉRATIF ET ÉDUCATION AU BRÉSIL : 30 ANS D'OMISSIONS ET D'AMBIVALENCES
}

\begin{abstract}
RESUMÉ : L'objectif de cet article est d'analyser comment les omissions et les ambivalences concernant la régulation de la coopération fédérative ont conduit à la délimitation et à la diffusion de formes de collaboration émanant d'organisations dont les intérêts corporatifs sont antagonistes aux intérêts de l'organisation de l'éducation sous la forme du système national. À partir d'une recherche bibliographique et documentaire, la coopération fédérative en matière d'éducation est discutée, bien que les omissions du Pouvoir Législatif concernant sa réglementation et la conduite ambivalente du Ministère de l'Éducation et du Secrétariat pour l'Articulation des Systèmes Éducatifs. Les conclusions indiquent l'avancement des propositions des organisations ayant des intérêts corporatifs au détriment de la bonne réglementation de la matière au moyen d'une Loi Complémentaire.
\end{abstract}

Mots-Clés : Fédéralisme coopératif. Régime de collaboration. Système National d'Éducation. Arrangements pour le développement de l'éducation. Mouvement "Collaborer avec l'Éducation ".

\section{Introdução}

$\mathrm{P}$

romulgada em 5 de outubro de 1988, a Constituição Federal (CF) completa 30 anos com 99 emendas e 119 artigos sem regulamentação (SCARTON, 2018). Em matéria de educação, a cooperação educativa, inscrita nos artigos 23 e 211, e o Sistema Nacional de Educação (SNE), que aparece com a nova redação dada ao artigo 214 pela Emenda Constitucional (EC) no 59/2009, ainda não foram regulamentados e têm se constituído em desafios para a promoção de políticas educacionais equânimes de acesso, permanência e qualidade num país desigual, de dimensóes continentais e com uma imensa dívida histórica quanto à garantia dos direitos sociais.

Além de constituir um dos maiores desafios para as políticas educacionais na assimétrica federação brasileira, a cooperação federativa tem sido um processo marcado por omissóes e ambivalências, no âmbito do Legislativo e do Executivo. Omissóes do Legislativo no sentido de deixar de cumprir o dever constitucional de regulamentação da matéria ao longo desses 30 anos. Ambivalências do Executivo no sentido de, havendo a possibilidade de pautar o referido dever constitucional quando já havia certo acúmulo e consenso na área de educação sobre o significado e o alcance do regime de colaboração, induzir para que o debate fosse direcionado por premissas e propostas diversas, muitas vezes antagônicas. 
O caso da atuação, desde o ano de 2012, da Secretaria de Articulação com os Sistemas de Ensino (SASE) no âmbito do Ministério da Educação (MEC), exemplifica essas ambivalências, uma vez que, ao mesmo tempo em que foi criada para viabilizar a instituição do SNE em regime de colaboração, apoiava propostas exógenas às dos movimentos sociais e de educadores no âmbito das Conferências Nacionais de Educação de 2008, 2010 e 2014.

Essas omissões e ambivalências vêm não só obstaculizando a atuação dos entes de forma interdependente e articulada, mas também favorecendo a implementação das propostas das organizaçóes de interesses empresariais. Tais interesses, além de não incidirem sobre a questão da cooperação federativa, difundem premissas privatizantes como as das adaptação e transferência de conhecimentos gerenciais desenvolvidos no setor privado para o público, bem como as da ênfase na eficiência, na eficácia e nos resultados tangíveis. Essas premissas podem ser observadas tanto nos Arranjos de Desenvolvimento da Educação (ADE) — disseminados pelo Movimento Todos Pela Educação (TPE) desde 2009 - como também — mais recentemente no ano de 2016 no Movimento Colabora Educação (MCE), grupo constituído de organizaçóes empresariais e pelo Banco Interamericano de Desenvolvimento, cujo objetivo é o fomento direto (por meio de assessoria e financiamento) às açóes de colaboração dos Estados e dos Municípios como “ condição necessária para a melhoria dos resultados de aprendizagem de todos" (MOVIMENTO COLABORA EDUCAÇÃO, 2018).

Desse modo, este artigo teve por objetivo problematizar como as omissóes e as ambivalências quanto à regulamentação da cooperação federativa vêm propiciando o delineamento e a difusão de formas de colaboração oriundas de organizações de interesses empresariais que são antagônicas aos interesses da organização da educação sob forma do sistema nacional, tal qual prescrito na Constituição.

A partir de pesquisa bibliográfica e documental, estruturamos a análise em quatro seçóes. Na primeira, com base em textos de Direito Constitucional e da área de educação, apresentamos os marcos conceituais e jurídicos da cooperação federativa na Carta de 1988. Na segunda seção, descrevemos as alteraçóes nos dispositivos constitucionais e infraconstitucionais que tiveram alguma incidência para a cooperação federativa em matéria educativa, sem, contudo, regulamentá-la. Na terceira seção, discorremos sobre as proposiçóes de regulamentação da cooperação federativa no âmbito do Legislativo que não lograram êxito, bem como sobre as ambivalências do Executivo, especialmente da SASE/MEC, que possibilitaram a priorização da proposta empresarial dos $\mathrm{ADE}$, em detrimento da expectativa das conferências de educação de que a SASE atuasse de maneira mais efetiva na instituição do SNE. Na quarta seção, analisamos como este cenário de omissóes e de ambivalências resultou na situação atual, em que as iniciativas para 
a instituição do SNE têm um prognóstico de estagnação, enquanto avançam propostas que têm por fundamento as formas de colaboração de matriz empresarial, com novos contornos e crescente nível de institucionalização, como é o caso do recente MCE.

\section{A cooperação federativa na Constituição Federal de 1988}

Diferentemente dos textos constitucionais anteriores, a Carta de 1988 não foi escrita por juristas, não se baseou em modelos do exterior nem foi resultado de ruptura de político- institucional pregressa, uma vez que foi delineada no decorrer do próprio processo de transição democrática, com ampla mobilização social durante 20 meses (SOUZA, 2005).

Outra diferença é que houve a possibilidade de os parlamentares constituintes decidirem pela manutenção ou não da organização do Estado brasileiro sob bases federativas, o que havia sido vetado nos processos constituintes anteriores.

O Texto aprovado em 1988 não só reafirmou a organização federativa do Estado brasileiro, como também reconheceu o município como ente federado (artigos $1^{\circ}, 18,29$ e 30). Além disso, inscreveu o federalismo cooperativo com entrelaçamento dos níveis de governo por meio das competências comuns (art. 23) e concorrentes (art. 24).

As competências comuns, de caráter administrativo, dizem respeito a todos os entes federados, inclusive ao município. Dessa forma, segundo o artigo 23, são responsabilidades conjuntas da federação brasileira, entre outras:

- $\quad$ o meio ambiente (incisos VI e VII);

- $\quad$ a saúde (inciso II);

- $\quad$ as instituições democráticas e o patrimônio público (inciso I);

- a cultura, a educação e a ciência (inciso V);

- $\quad$ a erradicação da pobreza (incisos VIII a X) (BRASIL, 1988).

Essas matérias requerem a cooperação federativa e boa parte delas foi tratada em capítulos específicos na seção da Constituição que dispóe sobre a Ordem Social (artigos 193 a 232).

Como todas essas matérias incluem a participação da União, a Constituição exige que a cooperação seja regulamentada por Lei Complementar, nos termos do parágrafo único do artigo 23: "Leis complementares fixarão normas para a cooperação entre a União e os Estados, o Distrito Federal (DF) e os Municípios, tendo em vista o equilíbrio do desenvolvimento e do bem-estar em âmbito nacio- 
nal" (BRASIL, 1988). Nesse sentido, a atuação conjunta, no pacto federativo sob os moldes cooperativos, tem por finalidade a realização de certa homogeneização para o alcance de resultados uniformes, sem que haja centralização de competências, mas sim relação de complementaridade com a definição das atribuições dos demais entes federados, a partir do macroplanejamento para as matérias de interesse comum (BERCOVICI, 2003; 2004).

Alguns requisitos de complementaridade e de macroplanejamento entre os entes federados podem ser observados, por exemplo, nos sistemas relativos à saúde, à cultura e à educação, pois requerem a atuaçáo conjunta de todos os entes federados (Uniáo, estados, DF e municípios). No caso da saúde, pela instituição de sistema único, conforme o disposto no caput e no $\$ 1^{\circ}$ do artigo 198; no caso da cultura, pela posterior inscrição do Sistema Nacional de Cultura, nos termos do artigo 216-A e; no caso da educação, pela organização dos sistemas de ensino e do sistema nacional em "regime de colaboração", segundo o disposto, respectivamente, no caput e nos parágrafos $1^{\circ}$ a $3^{\circ}$ do artigo 211 e no artigo 214 (MELCA, 2013).

No caso específico da educação, não houve a definição de como se dariam as açóes integradas dos entes federados para a prestação dos serviços educacionais para os cidadãos brasileiros em todo território nacional, por meio do regime de colaboração (artigo 211), de forma a garantir oferta de educação com padrão de qualidade (inciso VII artigo 206).

Embora tenham ocorrido avanços na Constituição e na legislação infraconstitucional quanto ao delineamento da coordenação e da cooperação federativa em matéria de educação, as modificaçóes pelas quais passou o Texto constitucional ao longo desses 30 anos tangenciaram o regime de colaboração, mas não o regulamentaram (ARAUJO, 2013; FARENZENA \& MARCHAND, 2013). A seguir, discutiremos o alcance de algumas dessas modificações.

\section{A cooperação e a colaboração federativa em matéria educacional ao longo dos 30 anos de vigência da Constituição Federal de 1988}

Quanto à forma de atuação dos entes federados, é importante salientar a diferença entre coordenação e cooperação federativa. Enquanto a coordenaçáo consiste no procedimento que busca um resultado comum, apesar da maneira separada e independente de atuação dos entes federados, cujas bases são as competências concorrentes do artigo 24 da Constituição de 1988, a cooperação está relacionada à tomada de decisão, que deve ser executada de forma conjunta, não podendo a União e os entes federados atuarem isoladamente (ARAUJO, 2013). 
Desse modo, há obrigatoriedade de cooperação para todos os entes federados, sem a possibilidade de atuação isolada. Ainda que a execuçáo propriamente dita possa ser realizada por cada um dos entes, parte de uma decisão tomada em conjunto relativamente a um interesse comum (BERCOVICI, 2004).

A educação é uma competência comum inscrita no artigo 23 que exige o equilíbrio entre coordenação e cooperação federativa e é exatamente disto que trata o artigo $211 \mathrm{da}$ CF ao definir as múltiplas funçóes dos entes federados: própria, supletiva e redistributiva. A função própria é aquela relativa ao âmbito de atuação prioritária dos entes federados, enquanto as funçóes supletiva e redistributiva expressam o regime de colaboração e o federalismo cooperativo em matéria educacional.

O artigo 23, ao longo desses 30 anos, teve alteraçóes relativas à compreensão de que as normas de cooperaçáo não poderiam estar fixadas numa só Lei Complementar para todas as matérias inscritas nos incisos desse artigo. Assim, do singular "Lei Complementar", a EC no 53/2006 modificou a redação para o plural, indicando que "Leis Complementares" definiriam as normas de cooperação, visando ao equilíbrio federativo (BRASIL, 1988).

Quanto ao artigo 211, o Texto aprovado em 1988 indicava que a Uniáo deveria financiar o seu sistema de ensino e o dos Territórios, bem como prestar assistência técnica e financeira aos demais entes federados para o atendimento à escolaridade obrigatória, e que os municípios deveriam atuar prioritariamente no ensino fundamental e pré-escolar.

Ao longo de 30 anos, o artigo foi alterado, respectivamente, pelas ECs no 14/1996, 53/2006 e 59/2009. A Emenda no 14/1996 deu nova redaçáo aos $\$ 1^{\circ}$ e $2^{\circ}$ e incluiu mais dois parágrafos no artigo $211 \mathrm{da} C F$, tratando respectivamente das etapas de atuação prioritária, ou seja, da função própria dos Estados e do DF (ensino fundamental e médio), e da previsão de que, na organização dos sistemas de ensino, Estados e Municípios deveriam definir formas de colaboração para assegurar o ensino obrigatório (à época o ensino fundamental). No ano de 2006, a Emenda no 53 introduziu mais um parágrafo (5) e, no ano de 2009, o $\$ 4^{\circ}$ é novamente alterado com a inclusão da União e do DF quanto à definição de formas de colaboração para assegurar o ensino obrigatório.

Entretanto, o artigo 23 não foi regulamentado e as modificaçóes que ocorreram no artigo 211 não possibilitaram avanços para a concretização do regime de colaboração. No artigo 211, em vez ser definida a colaboração como um instituto que viabilizaria a execuçáo conjunta dos serviços educacionais com mecanismos compartilhados de decisão, houve a inscrição da atuação prioritária $^{1}$ dos entes federados nas etapas de ensino, com a consequente transferência de responsabilidades. 
Mesmo que tenha ocorrido modificação nas funçóes da União na redação do artigo, o alcance das funções redistributiva e supletiva e da garantia do padráo de qualidade sáo questóes ainda hoje em aberto, se levarmos em conta o princípio da equidade para o equilíbrio federativo ${ }^{2}$. Como agravante, o custo aluno-qualidade inicial e o custo aluno-qualidade ${ }^{3}$ ainda náo foram definidos e implementados, considerando que seriam importantes instrumentos da responsabilidade solidária e da gestáo associada dos serviços públicos educacionais.

As ECs no 14/1996 e 53/2006, que instituem, respectivamente, o Fundo de Manutenção e Desenvolvimento do Ensino Fundamental e de Valorização do Magistério (Fundef) e o Fundo de Manutenção e Desenvolvimento da Educação Básica e de Valorização dos Profissionais da Educação (Fundeb), bem como os artigos 9, 10 e 11 da Lei no 9.394/1996 (Lei de Diretrizes e Bases da Educação Nacional — LDB), embora tenham delimitado o âmbito de ação de cada ente federado (função própria), não trataram diretamente da definição do regime de colaboração, pois reforçaram a atuação prioritária dos entes federados, que não expressa a totalidade da cooperação federativa.

Da mesma forma, o Plano Nacional de Educação (PNE) de 2001 a 2011 inscreveu o federalismo "autêntico" em matéria educativa, a partir da perspectiva da divisão de responsabilidades - com ênfase nas funçóes próprias de cada um deles — e da premissa vaga do "aprimoramento do regime de colaboração" não só entre os entes federados, mas também, "sempre que possível”, entre entes da mesma esfera federativa, mediante açóes conjuntas e realização de fóruns e de planejamento regionais, interestaduais e intermunicipais (BRASIL, 2001, p. 76). Tratou-se de mera prescrição sem efeitos práticos quanto à regulamentação e à concretização do regime de colaboração.

Por fim, a Emenda no 59/2009, ao mesmo tempo em que introduziu o $\$ 4^{\circ}$ no artigo 211 , prescrevendo que, na organização de seus sistemas de ensino, os entes federados definissem "formas de colaboração" de modo a garantir a universalização do ensino obrigatório, modificou o artigo 214, determinando que a lei deveria estabelecer o plano nacional de educação com o objetivo de articular o sistema nacional de educação, em regime de colaboração.

São exatamente as formas de colaboração inscritas no $\$ 4^{\circ}$ no artigo 211 que dispensam Lei Complementar e não os $\$ \$ 1^{\circ}$ a $3^{\circ}$ do artigo que tratam das relaçóes intergovernamentais para a oferta educativa, ao contrário do que vem sendo propalado por textos como os de Abicalil (2014), textos institucionais da SASE (BRASIL, 2015), bem como de organizaçóes de interesses empresariais como o MCE (2018).

Dessa forma, o argumento que sustenta a diferenciação entre cooperação e colaboração - tendo como referência que, no caso do artigo 23 , haveria 
necessidade de Lei Complementar ao passo que, no caso do artigo 211, a regulamentaçáo poderia ocorrer por diferentes vias legislativas e mesmo administrativas — compreende as formas de colaboraçáo inscritas no $₫ 4^{\circ}$ do artigo 211 como sinônimas do regime de colaboração, o que significa tomar a parte pelo todo.

A indistinção entre cooperação e colaboração federativa, além de constar de projetos que já tramitaram ou tramitam no Legislativo ${ }^{4}$, também consta do PNE 2014-2024 (BRASIL, 2014b), uma vez que a expressão "regime de colaboração" aparece 21 vezes (ARAÚJO, 2014), e a estratégia 20.9 traz expressamente a necessidade de regulamentar, por meio de Lei Complementar, os artigos 23 e 211 :

Regulamentar o parágrafo único do art. 23 e o art. 211 da Constituição Federal, no prazo de 2 (dois) anos, por lei complementar, de forma a estabelecer as normas de cooperaçáo entre a União, os Estados, o Distrito Federal e os Municípios, em matéria educacional, e a articulaçáo do sistema nacional de educação em regime de colaboraçáo, com equilíbrio na repartição das responsabilidades e dos recursos e efetivo cumprimento das funçóes redistributiva e supletiva da União no combate às desigualdades educacionais regionais, com especial atenção às regióes Norte e Nordeste (BRASIL, 2014b).

Dessa forma, tanto o artigo 23 quanto o artigo 211 precisam de regulamentação por meio de Lei Complementar, o que, após 30 anos de promulgação da CF de 1988 e 4 anos de aprovação do PNE (2014-2024), ainda não foi feito.

Cury (2008) indica que a omissão quanto à regulamentaçáo da matéria ao longo desses 30 anos tem, pelo menos, três protagonistas:

- os entes federados que receiam perder autonomia, num quadro de possível centralismo da União;

- os setores privados que associam a instituição de um sistema nacional de educação ao monopólio estatal e à restrição da liberdade de ensino;

- a própria União, que teme uma responsabilização maior com a educação básica, sobretudo no que concerne ao seu adequado financiamento.

Podemos acrescentar a essas omissóes os entraves históricos no âmbito do Legislativo em razão de vícios na tramitação dos projetos ou de arquivamento por fim de legislatura, bem como destacar o cenário recente de ambivalências que foram marcas distintivas da atuação do MEC, especialmente da 
SASE, durante o governo do Partido dos Trabalhadores (PT), o que passaremos a discutir na próxima seção.

\section{Cooperação Federativa em Educação: uma trajetória de omissões e ambivalências}

Foi no período entre os governos de Fernando Henrique Cardoso (1995-2002) e de Luiz Inácio Lula da Silva (2003-2010) que tiveram início as proposições legislativas para regulamentação da cooperação federativa em matéria de educação, tal qual disposto nos artigos 23 e 211 . Numa rápida apreciação sobre os projetos apresentados sobre a matéria, podemos destacar:

- Projeto de Lei (PL) no 1.946/96, do Deputado Maurício Requião (Partido do Movimento Democrático Brasileiro - PMDB-PR);

- $\quad$ PL no 4.553/1998, do Deputado Ivan Valente (PT-SP);

- $\quad$ PL no 4.283/2001, do Deputado Paulo Lima (PMDB-SP);

- $\quad$ PL no 237/2001, do Senador Ricardo Santos (Partido da Social Democracia Brasileira - PSDB-ES), arquivado em 2003 por fim de legislatura, sendo reapresentado com poucas alteraçóes em 2006, em seu mandato como deputado, em coautoria com o deputado Carlos Humberto Manato (Partido Democrático Trabalhista - PDT-ES), sob no 7.666 B/2006;

- Proposta de Emenda Constitucional (PEC) no 536/97, que deu origem à EC no 53/2006, bem como à Emenda Modificativa (EM) no 4/2005, propondo prazo para a regulamentaçáo do regime de colaboração de autoria do Deputado Ivan Valente (Partido Socialismo e Liberdade PSOL-SP) (CASSINI, 2011).

Como não foi aprovada $\mathrm{a}$ EM no 4/2005, o parlamentar Carlos Abicalil (PT-MT) apresentou a EM no 20, em 2005, que modificou a redação original do parágrafo único do artigo $23 \mathrm{da} \mathrm{CF} / 88$ (de lei complementar, no singular, para leis complementares, no plural). No conjunto, as proposiçôes não tramitaram, não incidiram sobre a matéria ou foram arquivadas por fim de mandato.

No Governo de Fernando Henrique Cardoso, houve a disputa com o Fórum Nacional em Defesa da Escola Pública (FNDEP) em torno da LDB, que começou a tramitar logo após a promulgação da CF de 1988 com a perspectiva de organização do SNE a partir de uma redefinição do papel do Governo Federal, derrotada pela proposta de pluralização de sistemas inscrita no substitutivo do Senador Darcy Ribeiro. 
Da mesma forma, a tramitação e a aprovação do PNE 2001-2011 não incidiram nem na cooperação federativa nem na constituição do SNE, tendo em vista a derrota no Congresso Nacional do projeto construído pela sociedade civil e pelos movimentos sociais reunidos nos Congressos Nacionais da Educação (CONED). Por conseguinte, como visto, a dimensão federativa constou de forma tímida no PNE, Lei no 10.172/2001 (BRASIL, 2001).

Diante desse quadro, no ano de 2002, o programa de governo da coligação do então candidato Luiz Inácio Lula da Silva — intitulado "Uma Escola do Tamanho do Brasil" — se comprometeu com:

- o encaminhamento de proposta de lei complementar para regulamentar a cooperação federativa;

- a instituição do SNE, com a criação de um "novo Conselho Nacional de Educação", incluindo a representação dos entes federados;

- a criação do Fórum Nacional de Educação (FNE) responsável pela realização de conferências quinquenais para propor, monitorar e avaliar o PNE e a existência de fóruns similares nas unidades subnacionais;

- o fortalecimento de órgãos de controle e acompanhamento social das políticas públicas de educação visando ao fim da fragmentação e dispersão de esforços (PARTIDO DOS TRABALHADORES, 2002).

Essa agenda foi parcialmente cumprida, com a criação, no ano de 2010, do FNE e a realização das conferências nacionais de educação. Contudo, não logrou êxito no que se refere aos encaminhamentos para a regulamentação da cooperação federativa e da instituição do SNE, principalmente em decorrência dos atravessamentos dos interesses de mercado que delinearam novos contornos para as políticas educacionais e para o debate sobre a definição da cooperação federativa.

No primeiro mandato do Governo Lula (2003-2006), foram tomadas medidas no sentido de fortalecer as parcerias público-privadas e de destinar verbas públicas para instituições particulares, tais como ProUni e a Lei de Inovação, que contrariavam o princípio basilar do FNDEP de verbas públicas para a educaçáo pública, desencadeando o rompimento de sindicatos e entidades da base governista com o FNDEP no ano de 2005 (LEHER, 2010). Além dessa inflexão aos interesses de mercado, desde o início da primeira gestão de Fernando Haddad, em 2005, organizaçóes de interesses empresariais se tornaram importantes interlocutoras do MEC por meio da influência do TPE5 , lançado em 2006, numa ampla ação de advocacy que buscava conciliar objetivos de justiça social (educação) aos do mundo corporativo. 
O primeiro sinal da atuação ambivalente do MEC quanto à cooperação federativa em matéria educacional foi no ano de 2007, mesmo antes da existência da SASE, pois, ao mesmo tempo em que promovia a Conferência Nacional de Educação Básica (CONEB) com o objetivo de construir "um Sistema Nacional Articulado de Educação, como consequência de um regime de colaboração" (BRASIL, 2007b, grifos do autor), o TPE se organizava em torno de metas e bandeiras que serviriam de base ao Plano de Desenvolvimento da Educação (PDE), lançado em 2007 pelo MEC. Vale lembrar que o PDE introduziu mecanismos de Planejamento entre os entes federados, por meio do Plano de Açóes Articuladas (PAR), bem como de aferição da qualidade, o Índice de Desenvolvimento da Educação Básica (IDEB) (BRASIL, 2007a).

Quanto às relaçóes entre os entes federados, o PDE se articulava a partir do enlace entre educação, território e desenvolvimento, de matriz empresarial, traduzida nos $\mathrm{ADE}$, um modelo adaptado dos arranjos produtivos locais, cuja premissa é a eficiência coletiva numa dada aglomeração territorial, constituindo-se em processos de cooperação entre empresas de determinada cadeia produtiva e o poder público para empreendimentos coletivos visando à otimização do poder de compra, à divisão de ônus, bem como de riscos e custos.

Dessa forma, percebe-se que o MEC buscava conciliar o inconciliável: a concepção de enlace entre educação, território e desenvolvimento, com a participação de organizaçóes de interesses empresariais, e o ideal de instituição do SNE, a partir da definição de responsabilidades compartilhadas entre os entes federados e do financiamento com maior participação da Uniáo.

Essa ambivalência teve uma longa trajetória quanto às medidas para a regulamentação da cooperação federativa e para a instituição do SNE. Logo no ano de 2009, ao mesmo tempo em que se inscrevia a necessidade de instituição do SNE na CF de 1988 com a nova redação dada ao artigo 214 pela EC no 59/2009, o Instituto Votorantim apresentava demanda de implantação de ADE em 12 municípios do Recôncavo Baiano para o TPE, com a perspectiva de territorialidade própria do campo empresarial, sendo que esta e outras iniciativas de implantação de ADE tiveram apoio do MEC.

No mesmo período, entre 2010 e 2014, foram promovidas, pelo Governo Federal, duas Conferências Nacionais de Educação (CONAE 2010 e 2014). Em ambos os eventos, fez-se constar nos documentos de referência e finais a necessidade da instituição do SNE e da regulamentação do regime de colaboração, tal como na CONEB de 2008.

Todavia, a proposta dos ADE era delineada como política pública por fora dos debates das CONAE. Sendo assim, no ano de 2011, foi aprovado, no Conselho Nacional de Educação (CNE), o Parecer no 9, "sobre proposta de fortalecimento e implementação do regime de colaboração mediante arranjos de de- 
senvolvimento da educação" (BRASIL, 2011b), que deu origem à Resolução no 1, homologada em 23 de janeiro de 2012 pelo MEC. Isso posto, na avaliação de Grin e Abrucio (2017, p. 46):

O CNE formalizou uma norma diante da realidade de muitos ADEs que se formaram com apoio de ONGs e, principalmente, de institutos e fundaçóes empresariais. Essas organizaçóes passaram a assessorar técnica e pedagogicamente os municípios, de forma regionalizada, visando aumentar a capacidade institucional das SMEs.

Simultaneamente à difusão da proposta dos $\mathrm{ADE}$ por organizações de interesses empresariais e à sua formalização pelo MEC, no Legislativo buscava-se legitimá-la ainda mais com a apresentação do projeto de Lei no 2.417/2011, do Deputado Alex Canziani (Partido Trabalhista Brasileiro PTB-PR), que propunha regulamentar os ADE como uma das formas do regime de colaboração.

A SASE, que havia sido criada em 2011 para instituir o SNE na dimensão da cooperação federativa, incorporou o que já vinha sendo delineado no MEC quanto ao reconhecimento e à promoção das propostas das organizaçóes de interesses empresariais, e nesse caso específico, instituiu o grupo de trabalho para elaborar estudos sobre a implementação de regime de colaboraçáo mediante Arranjos de Desenvolvimento da Educação (GT-ADE), por meio da Portaria no 1.238 do ano de 2012. Para tal, tomou por base as experiências recentes de $\mathrm{ADE}$ no país e as normativas emanadas do CNE sobre a matéria, com a clara influência do TPE.

No relatório sobre a constituição e o trabalho da SASE, Nogueira (2016, p. 2) indica que, em vez da ação de coordenação para a instituição do SNE, a SASE teria optado pela chamada "agenda instituinte", uma vez constatada a falta de consenso sobre a necessidade do sistema. A autora menciona "forças políticas externas" ao MEC e concepçóes contrárias ao SNE no interior do MEC, sem, contudo, identificá-las. E, ao reconhecer que havia a expectativa de apresentação de uma minuta de projeto de SNE na CONAE de 2014, assume que a opção foi pelo "caminho mais longo" com a discussão conceitual, o que se traduziu na divulgação de textos institucionais com baixa efetividade para os fins da ação de coordenação do MEC que se almejava.

Outro elemento importante a ser destacado é que se, para a SASE, não havia consenso sobre o SNE, havia muito menos entendimento sobre os $\mathrm{ADE}$, tendo em vista que não constituíam formas de colaboração com tradição no território brasileiro. Ao contrário, eram incipientes e estranhas ao debate e às políticas em matéria de colaboração federativa até então. Houve experiências bem-sucedidas de colaboração federativa nos estados do Mato Grosso, Rio Grande do Sul e 
Ceará, mas que não foram objeto de grupo de trabalho específico no interior da SASE, ao contrário dos ADE.

Assim, a SASE, apesar da reiteração sobre a necessidade de instituição do SNE por parte das conferências nacionais, preferiu assumir que havia dissensos, justificando a sua postura de tergiversação, ao passo que, no caso dos $\mathrm{ADE}$ - bem mais criticados, muito polêmicos e, portanto, nem um pouco consensuais - a opção foi pela institucionalização e estruturação de trabalho assegurado com várias reuniôes visando à consolidação de relatório, conforme a Portaria no 1.238/2012.

A aprovação do PNE (2014-2024) traduziu esse terreno movediço entre a agenda das CONAE em matéria de cooperaçáo federativa e a agenda das organizaçôes de interesses empresariais aglutinadas no TPE. Isso porque seu texto traz tanto a necessidade de regulamentação do regime de colaboraçâo (artigos 23 e 211) por via de Lei Complementar na estratégia 20.9, quanto a possibilidade de este ser fortalecido por meio dos $\mathrm{ADE}$, conforme o disposto no art. $7^{\circ}$ e no parágrafo $7^{\circ}$ do mesmo artigo:

Art. $7^{\circ}$ - A União, os Estados, o Distrito Federal e os Municípios atuarão em regime de colaboraçáo, visando ao alcance das metas e à implementaçáo das estratégias objeto deste Plano.

[...]

$\$ 7^{\circ} \mathrm{O}$ fortalecimento do regime de colaboração entre os $\mathrm{Mu}$ nicípios dar-se-á, inclusive, mediante a adoçâo de arranjos de desenvolvimento da educação. (BRASIL, 2014b).

Essa agenda de conciliação, em parte decorrente da atuação ambivalente da SASE, resultou na aprovação do PNE com a coexistência de dispositivos que remetem à necessidade da regulamentaçáo dos artigos 23 e 211 de forma articulada e à possibilidade da existência dos ADE. Pavimentou-se, assim, um terreno instável, onde ao mesmo tempo em que as propostas de regulamentaçáo da matéria náo avançam, as propostas que têm por fundamento as formas de colaboração de matriz empresarial ganham novos contornos e crescente nível de institucionalização. Esse é o caso do recente MCE que define o regime de colaboração como "a expressão que a Constituição emprega para se referir às formas voluntárias de cooperação entre os entes federados" (MOVIMENTO COLABORA EDUCAÇÃO, 2018, grifo nosso), definição que se opôe ao acúmulo das conferências de educação e também ao disposto no PNE.

\section{A cooperação federativa e o Sistema Nacional de Educação a partir do Plano Nacional de Educação}

Enquanto ainda estavam em andamento os trabalhos do GT-ADE da SASE, e levando em consideração o prazo de dois anos estabelecido na estratégia 
20.9, logo após a aprovação do PNE, em 27 de julho de 2014, foi apresentado o Projeto de Lei Complementar (PLP) no 413 pelo Deputado Ságuas Moraes (PT-MT), que objetivava "responder especificamente às disposiçóes do artigo 23 da Constituição Federal" (BRASIL, 2014a). A apresentação se deu de forma simultânea à tramitação do PLP no 15/2011 de autoria do Deputado Felipe Bornier (Partido Humanista da Solidariedade - PHS-RJ), que dispunha sobre normas para cooperação entre a Uniáo e os Estados, o DF e os Municípios, com ênfase na participação da União no regime de colaboração e o exercício de sua função redistributiva e supletiva, previstas no art. $211 \mathrm{da} \mathrm{CF}$ (BRASIL, 2011a). Como se vê, cada projeto tratando dos artigos isoladamente.

Em 24 junho de 2015, um ano após a aprovação do PNE, por meio da Portaria MEC no 619, foi instituída a instância de pactuação federativa que chegou a ser instalada em 27 de janeiro de $2016^{6}$. Após o ato de instalaçáo da instância de pactuação federativa, não houve medida digna de nota em relação à regulamentação do SNE no ano de 2016, tendo a equipe da SASE se modificado em maio deste ano.

No início de 2017, a SASE, com a nova equipe, retomou as medidas para viabilizar a estratégia 20.9 do PNE e, para tanto, publicou o Edital $\mathrm{n}^{\circ}$ $1 / 2017^{7}$ com o objetivo de contratar 29 consultores (distribuídos territorialmente pelo país) a fim de realizar levantamento sobre o funcionamento dos sistemas de ensino existentes no Brasil. Isso com o fim de servir de base à formação de Rede de Formação de Assistência Técnica que atuaria nos Estados e nos Municípios e de sustentar os debates sobre o regime de colaboração e sobre a instituição do SNE (BRASIL, 2017). Entretanto, já com o início dos trabalhos em curso por parte dos consultores, o edital foi cancelado em abril de 2017, sem explicaçóes técnicas, operacionais ou políticas que justificassem a interrupçáo.

Devido à descontinuidade, ao baixo nível de institucionalização e à pouca amplitude dos $\mathrm{ADE}$, as organizaçôes de interesses empresariais propuseram e implementaram um novo modelo de colaboração para a articulação dos grupos empresariais frente às agendas de reformas, como a Base Nacional Comum Curricular (BNCC), a Reforma do Ensino Médio e a Revisão do Fundeb (BORGES, 2017).

Assim, na perspectiva de uma agenda comum e coordenada para a área da educação, em outubro de 2016, o Banco Interamericano de Desenvolvimento (BID) promoveu uma reuniáo na sede do TPE, tendo por objetivo identificar a intenção das organizações de interesses empresariais em compor uma mesa temática intitulada "Regime de colaboração federativa na educação", no âmbito do Conselho Consultivo da Sociedade Civil (ConSoc) do banco. Além do TPE, aceitaram compor essa mesa temática a Fundação Itaú Social, a Fundação Lemann, o Instituto Ayrton Senna, o Instituto Natura, o Instituto Unibanco e o Instituto Positivo (ABRUCIO, 2017) ${ }^{8}$. 
No dia 30 de novembro de 2016, foi lançado o MCE, que declara ter por objetivo apoiar e fomentar a cooperação e a colaboração entre os entes federados na gestáo das políticas públicas de educação, com foco na melhoria do ensino e, para isso, pretende enfatizar duas açôes estratégicas: a produção e a disseminação de conhecimento sobre experiências de colaboração (BORGES, 2017).

Além da construção de um "Mapa das Experiências de Regime de Colaboraçáo em Educação", por meio da consulta a gestores públicos de todo o país, trabalho similar ao que seria realizado pela SASE por meio do edital cancelado, o MCE realizará estudos sobre os consórcios públicos multisetoriais que possuem câmaras de educação (sob a responsabilidade da Fundação Itaú Social) e a avaliação da implantação do PAR.

O BID tem interesse em apoiar técnica e financeiramente os ADE, bem como difundir o modelo de colaboraçáo do Pacto pela Aprendizagem na Idade Certa do Estado do Ceará, ação já iniciada no estado do Espírito Santo, com previsão de se estender para os estados do Amapá, Rio Grande do Norte e Maranhão. A razão de difusão desse modelo pode residir no seu potencial de institucionalização, já que, ao contrário dos $\mathrm{ADE}$, requer termos de cooperaçẫo dos Estados entre si e entre os Estados e os seus Municípios, com a possibilidade de inserção de organizaçóes empresariais e do terceiro setor para assessorar municípios quanto às definições de gestão, curriculares e de avaliação.

Assim, enquanto o BID e os agentes de interesse privado implementam modelos de colaboração, está cada vez mais distante a possibilidade de aprovação da regulamentação do regime de colaboração que institua o $\mathrm{SNE}^{9}$, tal como preconizado no PNE.

\section{Considerações finais}

São inegáveis as dificuldades inerentes à regulamentação da cooperação federativa e à instituição do SNE em decorrência dos múltiplos e complexos interesses em jogo ao longo da história da educação brasileira.

Mesmo considerando que as modificações na Constituição e na legislação infraconstitucional ao longo desses 30 anos tenham incidência na questão federativa em matéria educacional, ainda há enormes desafios como a institucionalização de instâncias de pactuação federativa democráticas e a definição e a implementação de mecanismos que assegurem a equidade na oferta, como é o caso do custo aluno-qualidade inicial e do custo aluno-qualidade, elencados na meta 20 do PNE, onde também consta a necessidade de regulamentação do regime de colaboração. 
Ao longo desses 30 anos, o Legislativo vem tentando regulamentar a matéria sem êxito, numa trajetória de omissóes que deve ser analisada em conjunto com interesses contrários da Uniáo, dos entes subnacionais e do setor privado.

A campanha de 2002 de Lula gerou expectativas quanto à reversão desse cenário, que foram se ampliando com a mobilização gerada pelas conferências de educação. Como demanda direta da CONAE 2010 foi criada a SASE com a expectativa de uma ação mais efetiva do MEC na coordenação dos trabalhos para instituição do SNE e da definiçấo do regime de colaboração.

Entretanto, a atuação ambivalente da SASE, a partir da alegação de falta de consenso sobre a necessidade de instituiçáo do SNE, mostrou, ao mesmo tempo, que houve hesitação quanto às medidas que eram defendidas nas conferências de educação e prontidão quanto às medidas que eram defendidas pelas organizaçóes de interesses empresariais, particularmente as do TPE, que não eram sequer reconhecidas e legitimadas pela área, como foi o caso dos ADE.

Sendo assim, atualmente temos um quadro de avanço das proposiçóes das organizaçōes de interesses empresariais - agora contando com ações coordenadas a partir do BID, como é o caso do $\mathrm{MCE}$ - e de improvável regulamentação do regime de colaboração e de instituição do SNE por via de Lei Complementar, o que era esperado desde 2008, com a realização da CONEB.

\section{Notas}

1. Cabe ressaltar que o termo "prioritária" não corresponde à competência (estrutura da federação), mas apenas à definição da área de atuação de cada ente, o que não exclui a educaçáo do rol de competências comuns.

2. Amaral Filho (2014, p. 319) assinala que as funções redistributiva e supletiva são afetas à solidariedade regional, pois visam à compensação dos entes federados com baixo poder de geração de receitas tributárias próprias: “A equalização fiscal tem por objetivo compensar as diferenças verificadas entre os estados subnacionais, em relação às suas capacidades de arrecadação, assim como as diferenças entre os custos dos serviços públicos, permitindo aos estados menos favorecidos a realização de uma oferta de serviços com taxas similares, mesmo em condiçôes de desigualdades de renda”.

3. O custo aluno-qualidade inicial está na estratégia 20.6 e o custo aluno-qualidade na estratégia 20.8 do PNE (2014-2024).

4. A título de exemplo, podemos citar mais remotamente a proposição do Projeto de Lei no 7.666 B, com a finalidade de regulamentar apenas o artigo 211 da CF de 1988, de autoria dos deputados Ricardo Santos (PSDB-ES) e Carlos Humberto Manato (PDT-ES), rejeitado por duas comissões de mérito por desconsiderar que a matéria deveria ser regulamentada em associação 
com o artigo 23, bem como a tramitação mais recente do PLP no 413/2014, do Deputado Ságua Moraes (PT-MT), que originalmente teve por objetivo regulamentar apenas o artigo 23, mas cujo substitutivo do relator, Deputado Glauber Rocha (PSOL-RJ), incorporou também a regulamentação do artigo 211.

5. Movimento da sociedade brasileira que reúne grandes grupos empresariais, como Grupo Gerdau (Presidência), Instituto Itaú, Fundação Bradesco, Itaú Social, Santander, Fundação Lemann, Instituto Natura, entre outros.

6. A composição da Instância de Pactuação Federativa está na Portaria no 986, de $1^{\circ}$ de outubro de 2015.

7. Como parte do Projeto no 914BRZ1139: Sistema Nacional Articulado de Educação: Políticas públicas pactuadas em regime de colaboração.

8. Além desse grupo original de organizaçôes, em 2018 também passou a integrar o MCE o Instituto Conceição Moura, organização privada sem fins lucrativos mantida pelo Grupo Moura com projetos na área de educação socioambiental e gestão escolar.

9. As últimas iniciativas que encaminham a estratégia 20.9 foram as modificaçôes na composição da Instância de Pactuação Federativa, por meio da Portaria no 50, de 23 de janeiro de 2017, e o apensamento ao PLP no 413/2014 do PLP no 448/2017, de autoria do Deputado Giuseppe Vecci, em dezembro de 2017 (PSDB/GO).

\section{Referências}

ABICALIL, C.A. O Plano Nacional de Educação e o regime de colaboração. Revista Retratos da Escola, Brasília, v. 8, n. 15, p. 249-263, jul./dez. 2014. Disponível em: <http:// retratosdaescola.emnuvens.com.br/rde/article/viewFile/440/571 >. Acesso em: 20 abr. 2018.

ABRUCIO, F.L. Cooperaçâo intermunicipal: experiências de arranjos de desenvolvimento da educação no Brasil. Curitiba: Positivo, 2017.

AMARAL FILHO, J. Princípios do federalismo: contribuiçóes metodológicas para sair do labirinto fiscalista. In: GUIMARÃES, P.F; AGUIAR, R.A.; LASTRES, H.M.M.; SILVA, M.M. (Orgs.). Um olhar territorial para o desenvolvimento: Nordeste. Rio de Janeiro: BNDES, 2014. p. 304-327. Disponível em: <https://web.bndes.gov.br/bib/jspui/ handle/1408/2801>. Acesso em: 21 abr. 2018.

ARAUJO, G.C. Federalismo e políticas educacionais no Brasil: equalização e atuação do empresariado como projetos em disputa para a regulamentação do regime de colaboração. Educação \& Sociedade, Campinas, v. 34, n. 124, p. 787-802, set./dez. 2013. Disponível em: <http://www.scielo.br/scielo.php?script=sci $\operatorname{arttext\& pid=S0101-}$ 73302013000300008\&lng=en\&nrm=iso $>$. Acesso em: 20 abr. 2018. http://dx.doi. org/10.1590/S0101-73302013000300008

ARAÚJO, L. O desafio do regime de colaboração no novo Plano Nacional de Educação. Jornal de Políticas Educacionais, n. 16, p. 59-65, jul./dez. 2014. Disponível em: < $\underline{\text { http:// }}$ www.jpe.ufpr.br/n16 6.pdf >. Acesso em: 24 jul. 2018. 
BERCOVICI, G. Desigualdades regionais, Estado e Constituição. São Paulo: Max Limonad, 2003.

. Dilemas do Estado federal brasileiro. Porto Alegre: Livraria do Advogado, 2004.

BORGES, J.M. Regime de Colaboração na Educação. In: CICLO DE PALESTRAS "EDUCAÇÃO EM DEBATE", 2017. Palestra..., 2017. Disponível em: < http:// www2.camara.leg.br/atividade-legislativa/comissoes/comissoes-permanentes/ce/

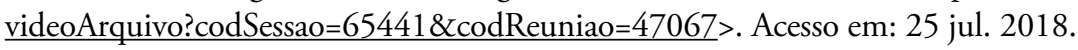

BRASIL. Câmara dos Deputados. Projeto de Lei Complementar PLC no 15/2011. Estabelece normas para cooperaçáo entre a União e os Estados, o Distrito Federal e os Municípios, com relação à responsabilidade na gestão pública da educação escolar brasileira. 2011a. Disponível em: <http://www.camara.gov.br/proposicoesWeb/ fichadetramitacao?idProposicao=492957>. Acesso em: 25 abr. 2018.

. Câmara dos Deputados. Projeto de Lei Complementar PLC no 413/2014. O presente Projeto de Lei Complementar visa responder especificamente às disposiçóes do artigo 23 da Constituição Federal, acelerada, agora, pela recente sanção da Lei no 13.005/2014 que estabelece o Plano Nacional de Educação e dá outras providências. 2014a. Disponível em: <http://www.camara.gov.br/proposicoesWeb/fichadetramitacao?idProposicao=620859 >. Acesso em: 25 abr. 2018.

- Constituição da República Federativa do Brasil. Brasília: Senado Federal, 1988. Disponível em: <http://www.planalto.gov.br/ccivil 03/constituicao/ constituicaocompilado.htm>. Acesso em: 20 mar. 2018.

Decreto no 6.094, de 24 de abril de 2007. Dispóe sobre a implementação do Plano de Metas Compromisso Todos pela Educação, pela União Federal, em regime de colaboração com Municípios, Distrito Federal e Estados, e a participação das famílias e da comunidade, mediante programas e açóes de assistência técnica e financeira, visando a mobilização social pela melhoria da qualidade da educação básica. Diário Oficial da União, Brasília, 24 abr. 2007a.

. Lei no 10.172, de 9 de janeiro de 2001. Estabelece o Plano Nacional de Educação. Diário Oficial da União, Brasília, 10 jan. 2001.

. Lei no 13.005, de 25 de junho de 2014. Aprova o Plano Nacional de Educação PNE e dá outras providências. Diário Oficial da União, Brasília, 26 jun. 2014 b.

. Ministério da Educação. Secretaria de Articulação com os Sistemas de Ensino. Diretoria de Articulação com os Sistemas de Ensino. Instituir um Sistema Nacional de Educação: agenda obrigatória para o País. 2015. Disponível em: <http://pne.mec.gov.br/ images/pdf/SNE_junho_2015.pdf>. Acesso em: 24 abr. 2018.

- Ministério da Educação. Secretaria de Articulação com os Sistemas de Ensino. Edital 01/2017. Termo de referência para contratação de pessoa física (consultor por produto). 2017. Disponível em: <http://portal.mec.gov.br/index.php?option=com docman\&view=download \&alias=60151-tor-edital-01-2017-914brz1139-pdf\&category_ slug=fevereiro-2017-pdf\&Itemid=30192>. Acesso em: 28 abr. 2018. 
Parecer $n^{\circ}$ 9, de 30 de agosto de 2011. Análise de proposta de fortalecimento e implementação do regime de colaboração mediante arranjos de desenvolvimento da educação. Ministério da Educação. Conselho Nacional de Educação, 2011b. Disponível em: <http://www.portal.mec.gov.br>. Acesso em: 2 abr. 2018.

Regimento Interno da Conferência Nacional da Educação Básica - CONEB, definido pela Comissáo Organizadora, conforme o que dispóe a Portaria Normativa $n^{\circ} 11$, do Ministério da Educação - MEC. Brasília, 24 abr. 2007b.

CASSINI, S.A. Federação e Educação no Brasil: a atuação do poder legislativo nacional para regulamentação do regime de colaboração. 143 f. Dissertação (Mestrado em Educação) Programa de Pós-Graduação em Educação, Universidade Federal do Espírito Santo, Vitória, 2011.

CURY, C.R.J. Sistema Nacional de Educação: desafio para uma Educação igualitária e federativa. Educação \& Sociedade, Campinas, v. 29, n. 105, p. 1187-1209, set./dez. 2008. Disponível em: <http://www.scielo.br/pdf/es/v29n105/v29n105a12.pdf $>$. Acesso em: 3 abr. 2018.

FARENZENA, N.; MARCHAND, P.S. Relaçôes intergovernamentais na educação à luz do conceito de regulação. Cadernos de Pesquisa, São Paulo, v. 43, n. 150, p. 788-811, dez. 2013. Disponível em: <http://www.scielo.br/scielo.php?script=sci_arttext\&pid=S010015742013000300004\&lng=en\&nrm=iso $>$. Acesso em: 20 jul. 2018. http://dx.doi. org/10.1590/S0100-15742013000300004

GRIN, E.J; ABRUCIO, F.L. Inovação no associativismo territorial no Brasil: os arranjos de desenvolvimento da educação. Redes, Santa Cruz do Sul, v. 22, n. 3, set-dez. 2017. Disponível em: <https://www.researchgate.net/publication/319621159 Inovacao no associativismo territorial no Brasil os Arranjos de Desenvolvimento da Educacao $>$. Acesso em: 30 abr. 2018. http://dx.doi.org/10.17058/redes.v22i3.10408

LEHER, R. A educação no Governo Lula da Silva: a ruptura que não aconteceu. In: MAGALHÁES, J.P. de A.; FIGUEIRAS, L.; PINHEIRO, B.; PHILIGRET, C.; BALANÇO, P.; BRUNO, M.; CARCANHOLO, M.D.; MINEIRO, A.S.; GONÇALVES, R.; CANO, W.; SILVA, A.L.G.; LESSA, C.; PÁDULA, R.; SANTOS, G.; DOWELL, F.M.; TAUTZ, C.; SISTON, F.; PINTO, J.R.L.; BADIN, L. OLIVEIRA, A.U.; TOMELLI, F.; QUEIROZ, A.C.; BAHIA, L.; LEHER, R.; DELGADO, G.C. Os anos Lula: contribuições para um balanço crítico 2003-2010. Rio de Janeiro: Garamond, 2010.

MELCA, A.J.M. Gestão associada de serviços públicos no Brasil: federalismo cooperativo, administração pública e direitos fundamentais. $172 \mathrm{f}$. Dissertação (Mestrado Acadêmico em Direito) - Faculdade de Direito, Universidade Federal do Ceará, Fortaleza, 2013.

MOVIMENTO COLABORA EDUCAÇÃO. Apresentação. Movimento Colabora Educação, 2018. Disponível em: <http://movimentocolabora.org.br/quem-somos/>. Acesso em: 15 jul. 2018.

NOGUEIRA, F. A nossa SASE. Brasília, 13 maio 2016. Disponível em: <https:// avaliacaoeducacional.files.wordpress.com/2016/05/a-historia-da-sase1.pdf $>$. Acesso em: 19 jul. 2018. 
PARTIDO DOS TRABALHADORES. Uma escola do Tamanho do Brasil. Resoluçóes de Encontros e Congressos \& Programas de Governo. São Paulo: Partido dos Trabalhadores/ Fundação Perseu Abramo, 2002.

SCARTON, S. Constituição aguarda regulamentação de quase 120 dispositivos. Jornal do Comércio, Porto Alegre, 12 jun. 2018. Caderno Jornal da Lei. Disponível em: <https:// www.jornaldocomercio.com/ conteudo/cadernos/jornal da lei/2018/06/631261-cartaaguarda-regulamentacao-de-quase-120-dispositivos.html>. Acesso em: 11 jul. 2018.

SOUZA, C. Federalismo, desenho constitucional e instituições federativas no Brasil pós-1988. Revista de Sociologia e Política, Curitiba, n. 24, p. 105-121, jun 2005. Disponível em: <http://www.scielo.br/scielo.php?script=sci_arttext\&pid=S010444782005000100008\&lng=en\&nrm=iso>. Acesso em: 20 mar. 2018. http://dx.doi. org/10.1590/S0104-44782005000100008

Recebido em 19 de maio de 2018.

Aceito em $1^{\circ}$ de outubro de 2018. 